\title{
DESIGN DE EQUIPAMENTO DE TECNOLOGIA ASSISTIVA: acessório facilitador de digitação para usuária com Fibrodisplasia Ossificante Progressiva
}

\author{
ASSISTIVE TECHNOLOGY EQUIPMENT DESIGN:typing \\ facilitator accessory for user with progressive ossificans fibrodysplasia
}

\author{
Andréa Katiane Ferreira Costa ${ }^{1}$, Mestre. \\ Samuel Renato de Oliveira Silva ${ }^{2}$, Mestrando. \\ Rubenio dos Santos Barros ${ }^{3}$, Bacharel em Design. \\ Lívia Flávia de Albuquerque Campos ${ }^{4}$, Dra. \\ (1) Universidade Federal do Maranhão \\ e-mail: andrea.katianefc@gmail.com \\ (2) Universidade Federal do Maranhão \\ e-mail: samuelrosilva@gmail.com \\ (3) Universidade Federal do Maranhão \\ e-mail: rubeniobarros@hotmail.com \\ (4) Universidade Federal do Maranhão \\ email:liviaflavia@gmail.com
}

Design, FOP, tecnologia assistiva, digitação.

O presente artigo trata do desenvolvimento de um acessório facilitador para digitação para uma usuária com Fibrodisplasia Ossificante Progressiva, enfermidade que gera malformações esqueléticas ocasionando uma conseqüente imobilização e deformação articular. Apresentam-se informações preliminares para o conhecimento das necessidades da usuária, pesquisa de similares e desenvolvimento, observando-se baixo custo, fácil manuseio e funcionalidade, culminando no desenvolvimento do protótipo.

Design, Progressive Ossificans Fibrodysplasia, assistive technology, typing.

The present article deals with the development of a facilitator accessory for typing for a user with Progressive Ossificans Fibrodysplasia, a disease that causes skeletal malformations, resulting in immobilization and joint deformation. Preliminary information is presented for the user's knowledge of the needs, research of similar and development, observing low cost, easy handling and functionality, culminating in the development of the prototype. 


\section{Introdução}

A Tecnologia Assistiva (TA) é um termo utilizado para identificar todo o arsenal de recursos e serviços que contribuem para proporcionar ou ampliar habilidades funcionais de pessoas com deficiência e conseqüentemente promover vida independente e inclusão (BERSCH \& TONOLLI, 2006).

A ADA - American with Disabilities Act, define a TA como "uma ampla gama de equipamentos, serviços, estratégias e práticas concebidas e aplicadas para minorar os problemas funcionais encontrados pelos indivíduos com deficiências" (COOK \& HUSSEY, 1995)

É por meio de adaptações em ferramentas, materiais ou equipamentos que a TA permite facilitar a função manual, ampliando a participação do indivíduo em atividades rotineiras (CAVALCANTI; GALVÃO, 2007).

Assim, tais materiais e produtos favorecem desempenho autônomo e independente em tarefas rotineiras ou facilitam o cuidado de pessoas em situação de dependência de auxílio, nas atividades como se alimentar, cozinhar, vestir-se, tomar banho e executar necessidades pessoais. São exemplos destes produtos os talheres modificados, suportes para utensílios domésticos, abotoadores, recursos para transferência, barras de apoio, equipamentos dentre muitos outros (BERSCH, 2017).

Para Bersch (2017) as categorias de produtos de TA incluem:

- Auxílios para a vida diária e vida prática

- CAA - Comunicação Aumentativa e Alternativa

- Recursos de acessibilidade ao computador

- Sistemas de controle de ambiente

- Projetos arquitetônicos para acessibilidade $6^{\circ}$ Ergodesign - Congresso Internacional de Ergonomia e Usabilidade e Interfaces Humano Tecnológica: Produto, Informações Ambientes onstruídos e Transporte

$6^{\circ}$ USIHC - Congresso Internacional de Ergonomia e Usabilidade de Iterfaces Humano Computador

INAHPA | 2017 - Congresso Internacional de Ambientes Hipermídia ara Aprendizagem.

- Produtos para Adequação Postural

- Produtos para Auxílios de mobilidade

- Auxílios para qualificação da habilidade visual e recursos que ampliam a informação a pessoas com baixa visão ou cegas

- Auxílios para pessoas com surdez ou com déficit auditivo

- Mobilidade em veículos

Abaixo, onde consta "portador de deficiência" atualmente lê-se pessoa com deficiência.

O Decreto 3.298 de 1999, artigo 19, ressalta do direito do cidadão brasileiro com deficiência às Ajudas Técnicas (BRASIL, 1999):

Art. 19. Consideram-se ajudas técnicas, para os efeitos deste Decreto, os elementos que permitem compensar uma ou mais limitações funcionais motoras, sensoriais ou mentais da pessoa portadora de deficiência, com o objetivo de permitirlhe superar as barreiras da comunicação e da mobilidade e de possibilitar sua plena inclusão social.

Parágrafo único. São ajudas técnicas:

I - próteses auditivas, visuais e físicas; II - órteses que favoreçam a adequação funcional; III - equipamentos e elementos necessários à terapia e reabilitação da pessoa portadora de deficiência; IV - equipamentos, maquinarias e utensílios de trabalho especialmente desenhados ou adaptados para uso por pessoa portadora de deficiência; $\mathrm{V}$ - elementos de mobilidade, cuidado e higiene pessoal necessários para facilitar a autonomia e a segurança da pessoa portadora de deficiência;

VI - elementos especiais para facilitar a comunicação, a informação e a sinalização para pessoa portadora de deficiência; VII - equipamentos e material pedagógico especial para educação, capacitação e recreação da pessoa portadora de deficiência;
Realização:

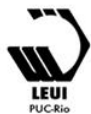




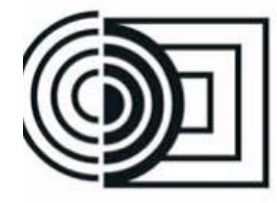

VIII - adaptações ambientais e outras que garantam o acesso, a melhoria funcional e a autonomia pessoal; e

IX - bolsas coletoras para os portadores de ostomia.

Ainda, o Brasil ratificou a Convenção sobre os Direitos das Pessoas com deficiência da ONU e a incorporou ao seu ordenamento jurídico conferindo-lhe equivalência constitucional promulgado no DECRETO No 6.949, DE 25 DE AGOSTO DE 2009, do qual ressalta-se (BRASIL, 2009):

Artigo 4. Obrigações gerais.

\section{$[\ldots]$}

g) Realizar ou promover a pesquisa e o desenvolvimento, bem como a disponibilidade e o emprego de novas tecnologias, inclusive as tecnologias da informação e comunicação, ajudas técnicas para locomoção, dispositivos e tecnologias assistivas, adequados a pessoas com deficiência, dando prioridade a tecnologias de custo acessível;

Assim, o objetivo deste trabalho é desenvolver um acessório facilitador para digitação em teclado de computador, urna eletrônica e demais terminais informatizados, destinado à uma usuária específica, com Fibrodisplasia Ossificante Progressiva (FOP) que consiste em uma doença genética rara do tecido conjuntivo, caracterizada por ossificação disseminada em tecidos moles e alterações congênitas das extremidades. O início ocorre na infância e gera uma conseqüente imobilização e deformação articular (ARAUJO JUNIOR et. al, 2005).

O desenvolvimento de um produto que a auxilie nos trabalhos com o computador e demais terminais informatizados poderá contribuir para a melhoria na independência, qualidade de vida e inclusão social da referida usuária com deficiência. $6^{\circ}$ Ergodesign - Congresso Internacional de Ergonomia e Usabilidade e Interfaces Humano Tecnológica: Produto, Informações Ambientes onstruídos e Transporte

$6^{\circ}$ USIHC - Congresso Internacional de Ergonomia e Usabilidade de iterfaces Humano Computador

INAHPA | 2017 - Congresso Internacional de Ambientes Hipermídia ara Aprendizagem.

\section{Referencial Teórico}

\subsection{O deficiente e a sociedade}

É necessário distinguir a palavra deficiente da palavra doente, que costumam confundir a opinião pública. As pessoas deficientes não são necessariamente pessoas doentes, no entanto, algumas doenças geram deficiências, que deixam sequelas como a F.O.P. "Doente adj. Que tem doença; que sofre incômodo moral. Deficiência adj. Imperfeito; em que há deficiência”. (Moderno Dicionário Enciclopédico Brasileiro. 1971. p 237 e 269)

O decreto $\mathrm{N}^{\circ} 6.949$, DE 25 DE AGOSTO DE 2009 define (BRASIL, 2009):

Pessoas com deficiência são aquelas que têm impedimentos de longo prazo de natureza física, mental, intelectual ou sensorial, os quais, em interação com diversas barreiras, podem obstruir sua participação plena e efetiva na sociedade em igualdades de condições com as demais pessoas.

Os princípios do referido Decreto garantem:

a) $O$ respeito pela dignidade inerente, a autonomia individual, inclusive a liberdade de fazer as próprias escolhas, e a independência das pessoas;

b) A não-discriminação;

c) A plena e efetiva participação e inclusão na sociedade;

d) $O$ respeito pela diferença e pela aceitação das pessoas com deficiência como parte da diversidade humana e da humanidade;

e) A igualdade de oportunidades;

f) A acessibilidade;

g) A igualdade entre o homem e a mulher;

h) $\mathrm{O}$ respeito pelo desenvolvimento das capacidades das crianças com deficiência e pelo direito das crianças 


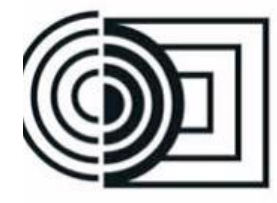

com deficiência de preservar sua identidade.

Tais garantias ressaltam a independência e a inclusão social das pessoas com deficiência. Assim independente do meio em que vivem, as pessoas com deficiência, não só necessitam como têm direito ao trabalho, independência, lazer, respeito, amor e vida social como qualquer outro cidadão.

\subsection{Fibrodisplasia Ossificante Progressiva (FOP)}

A FOP foi relatada pela primeira vez em 1693 por Guy Patin ("mulher de madeira"), mas só foi descrita cientificamente em 1736, pelo médico John Freke, em comunicação na Real Sociedade de Medicina de Londres. Em 1924, foi dividida em três categorias: miosite ossificante progressiva, miosite ossificante circunscrita progressiva e miosite ossificante circunscrita. Em 1969 foi unificada como FOP, que abrange a afecção de tecidos moles, além do músculo (JESUS GARCIA-PINZAS et al, 2013).

Segundo os autores a FOP é uma condição rara de malformações esqueléticas que produz um osso novo em lugares onde este não deveria existir, levando, com o tempo, à imobilidade permanente. Afeta igualmente homens e mulheres, sendo calculada atualmente uma prevalência global de aproximadamente um caso a cada 2 milhões de indivíduos.

A FOP é uma enfermidade incapacitante em crianças e adultos jovens. O doente geralmente apresenta ossificação progressiva do tecido conjuntivo, que causa uma limitação crescente da mobilidade osteoarticular, afetando principalmente a coluna vertebral, ombros, quadril e articulações periféricas. O paciente assume uma postura única e limitada, não podendo sequer sentar. Este aspecto caracteriza a forma avançada da doença, recebendo a denominação de síndrome do "stone man", antes descrita em apenas cerca de 600 doentes. Nesse estágio, o paciente $6^{\circ}$ Ergodesign - Congresso Internacional de Ergonomia e Usabilidade e Interfaces Humano Tecnológica: Produto, Informações Ambientes onstruídos e Transporte

$6^{\circ}$ USIHC - Congresso Internacional de Ergonomia e Usabilidade de iterfaces Humano Computador

INAHPA | 2017 - Congresso Internacional de Ambientes Hipermídia ara Aprendizagem.

rapidamente evolui para a morte, em conseqüência de problemas respiratórios de origem restritiva (ARAUJO JUNIOR et al, 2005).

\section{Métodos e Técnicas}

Para o desenvolvimento projetual, utilizou-se como base o processo de design apresentado por Löbach (2001), que divide o processo criativo em 4 (quatro) etapas, sendo elas:

a) análise do problema - que é o ponto de partida e a motivação do processo de design e que envolve a coleta de informações. Através do levantamentos dos dados é possível identificar e fazer o julgamento dos diversos fatores considerados no projeto (LOBACH, 2001). Nesta pesquisa, a análise do problema inclui o levantamento bibliográfico, entrevistas com pessoas especializadas na área da doença causadora da deficiência (F.O.P.); e com a pessoa com a deficiência. Foi feita ainda a análise comparativa de produtos, de modo a identificar deficiências e valores que devem ser aprimorados no produto em desenvolvimento (LOBACH, 2001).

b) Geração de alternativas - é a fase de produção de ideias com base nas análises realizadas, com o objetivo do desenvolvimento e aperfeiçoamento de alternativas ao problema.

c) Avaliação das alternativas - é a fase de confrontamento das ideias com os critérios estabelecidos, de modo a identificar qual a proposta mais viável e que melhor se adequa às necessidades da usuária.

d) Realização da solução do problema corresponde a materialização da alternativa escolhida, de modo a proporcionar bons resultados quanto a ergonomia, fabricação, material, resistência, custo, acabamento, peso,
Realização:

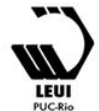




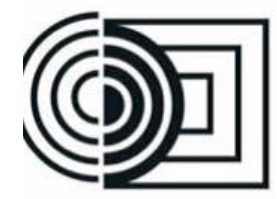

etc. Esta etapa culminou em um protótipo.

e) Detalhamento do Projeto desenvolvimento do material representativo e de detalhamento do produto, o que corresponde aos desenhos técnicos (vistas, cortes, detalhes de encaixes e perspectivas).

\section{Resultados e Discussões 4.1 Contato com a usuária}

Observando as limitações das pessoas com deficiências físicas, e o seu potencial remanescente, escolheu-se desenvolver um produto capaz de facilitar a vida no que diz respeito a utilização do computador e de outros terminais informatizados, como por exemplo as urnas eletrônicas. Cada deficiência e mais especificamente cada indivíduo, precisa ter seu acessório, voltado para suas necessidades e limitações, que são praticamente individuais, pois cada caso apresenta suas peculiaridades, que merecem atenção particular.

Sendo assim, partiu-se para o estudo do usuário. Através de associações de deficientes físicos como: o C.V.I. (Centro de Vida Independente), foi possível o contato com a Associação de Lesionados Medular (ALM), onde houve o contato com pessoas com deficiências físicas, entre eles a usuária com FOP, que forneceu informações sobre as particularidades de sua deficiência. A refererida usuária tinha escoliose e depois de uma cirurgia na coluna foi diagnosticada com FOP, aos 15 anos, o médico revelou seu estado de saúde agravado pela cirurgia. Durante a análise do problema, percebeu-se a falta de interesse de profissionais especializados em estudar a síndrome e o potencial indivíduo com FOP,

\subsection{Análise do problema}

Para escolha e desenvolvimento de um acessório adequado a pessoas com deficiência, faz-se necessário conhecer e saber quais são as suas necessidades físicas, funcionais e o estilo $6^{\circ}$ Ergodesign - Congresso Internacional de Ergonomia e Usabilidade e Interfaces Humano Tecnológica: Produto, Informações Ambientes onstruídos e Transporte

$6^{\circ}$ USIHC - Congresso Internacional de Ergonomia e Usabilidade de iterfaces Humano Computador

INAHPA | 2017 - Congresso Internacional de Ambientes Hipermídia ara Aprendizagem.

de vida do futuro usuário, fazendo uma avaliação com experimentação, se possível de tamanho e características específicas, pois os equipamentos são adaptados ao usuário e não o contrário.

O facilitador ou splint de mão para digitação, é um produto para pessoas com deficiências físicas que possibilita a digitação, facilitando ou ainda substituindo a função da mão diante do computador. $\mathrm{O}$ usuário pode ser: $\mathrm{o}$ paraplégico com lesão completa; o tetraplégico com lesão parcial; a pessoa com paralisia cerebral (P.C.) leve ou moderadamente afetada; a pessoa com Doença Cérebrovascular (AVC) e outras deficiências, no entanto o produto a ser desenvolvido neste trabalho é específico para a usuária com F.O.P. Fibrodisplasia Ossificante Progressiva.

\subsubsection{Dimensionamento Antropométrico do Produto}

De acordo com as necessidades da usuária e o objetivo a ser alcançado, selecionou-se medidas antropométricas importantes para o desenvolvimento do produto. A pesquisa foi realizada através da tomada de medidas objetivas. Foram utilizadas medidas macro (maiores dimensões do corpo humano como antebraço) e micro (como medidas das mãos) através do método direto de tomada de medidas. Foi montada a tabela de dimensões com medidas do braço, antebraço, mão e dedos (antropometria estática - corpo parado ou com pequenos movimentos). A usuária não possui muitos movimentos como de ombro e tronco (parte da conjugação de músculos) para realização da atividade de digitar. Assim, o alcance da usuária em questão foi medido através de testes com uma antena. Para completar o estudo antropométrico e análise de melhores formas de engate, manejo e controle da usuária utilizou-se o recurso da fotografia, documentando fases do processo.
Realização:

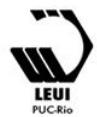


$6^{\circ}$ USIHC - Congresso Internacional de Ergonomia e Usabilidade de iterfaces Humano Computador

INAHPA | 2017 - Congresso Internacional de Ambientes Hipermídia ara Aprendizagem.

\subsection{Pesquisa de Similares: Tipologia de Facilitador de mão}

Identificou-se vários tipos de facilitadores para a vida diária também conhecidos como órteses facilitadoras. Estas informações foram obtidas através de pesquisas bibliográficas em livros, catálogos, revistas, junto a profissionais da área e a possíveis usuários. Dentre os principais destacam-se os facilitadores de punho e polegar, o facilitador dorsal e o Facilitador Palmar (Figura 1)
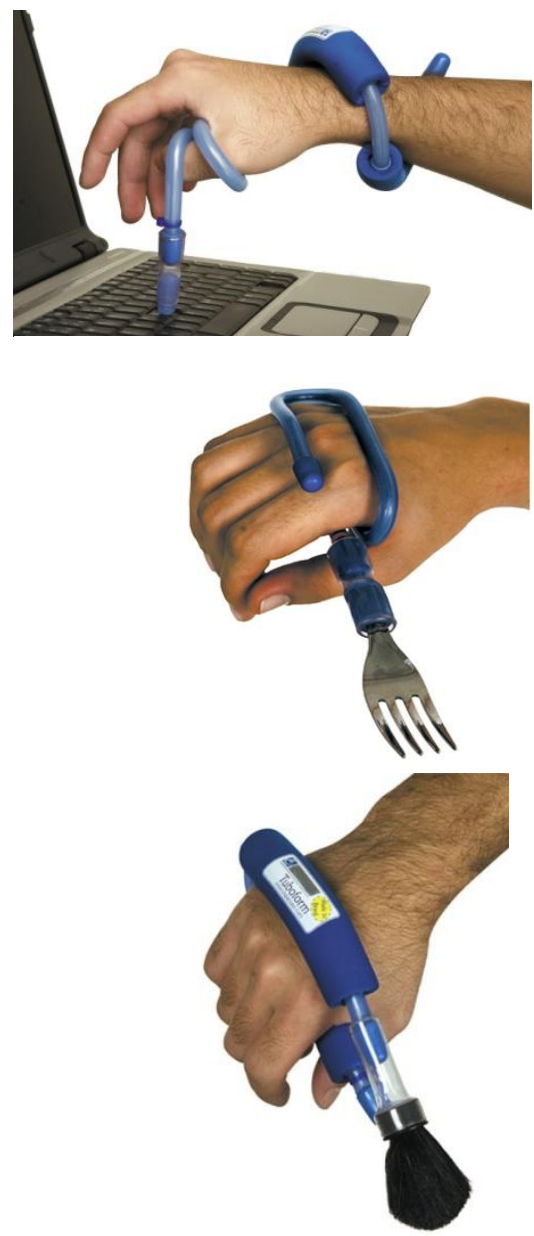

Figura 1 - Facilitadores de punho e polegar; facilitador dorsal; facilitador palmar. Fonte: CirúrgicaExpress (2015).

\subsection{Requisitos do projeto}

a) O produto deve ser de leitura simples, permitindo ao usuário e demais pessoas entenderem o funcionamento ao olharem o objeto;

b) Deve possuir coerência formal;

c) Deve ser simples e estar de acordo com a realidade do usuário;

d) Deve aumentar o potencial do usuário;

e) Deve ser funcional, leve, resistente;

f) Os materiais e processos de fabricação devem estar de acordo com o produto, utilizando-se tecnologia simples e local.

\subsection{Geração de alternativas}

Nesta etapa do trabalho, as ideias foram evoluindo gradativamente revelando o processo criativo e por fim analisadas de acordo com os requisitos do projeto.

A proposta 1 (Figura 2) possui forma simples, diminuindo o fator estigmatizante; ponteira revestida em borracha evitando deslizes nas teclas do computador; encaixe para o dedo e o corpo do acessório através de suporte em forma de "S".

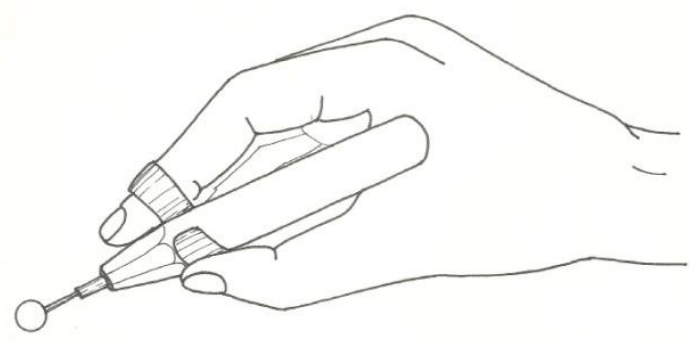

Figura 2 - Proposta 01.

A proposta 2 (Figura 3) possui forma simples; maior segurança devido ao encaixe (indicador - corpo - polegar) o apoio ao polegar aumenta a estabilidade. 

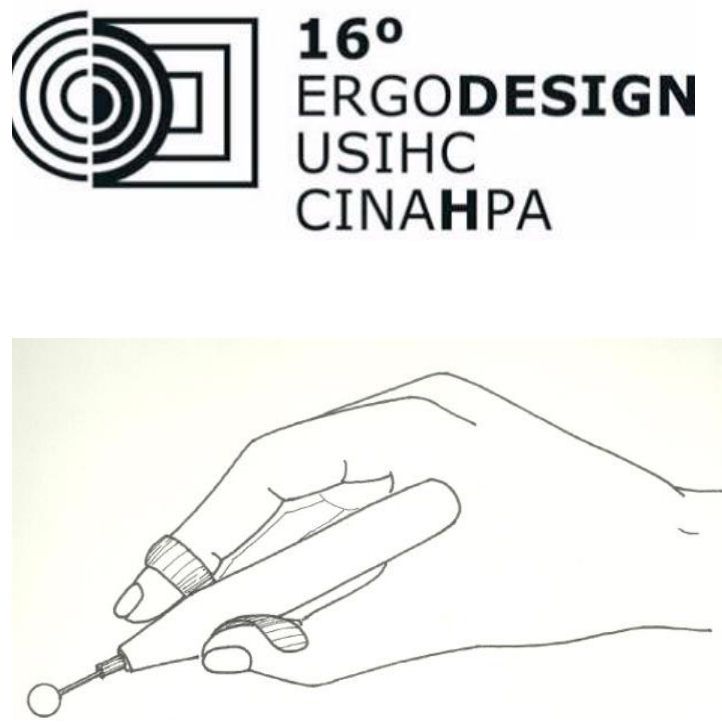

Figura 3 - proposta 02.

Com a proposta 3 (figura 4), foi concluído que um anel para encaixe do polegar é suficiente para dar estabilidade ao usuário. $\mathrm{O}$ anel possui pequena esfera que proporciona movimento de giro e maior liberdade de uso.

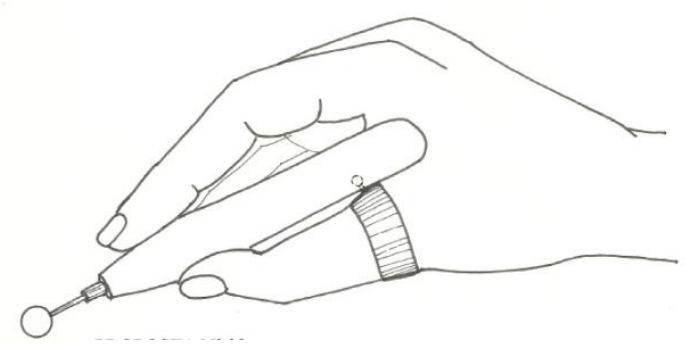

Figura 4 - Proposta 03.

Com o corpo formado por anéis em borracha A proposta 4 (figura 5) propõe aumentar o conforto e evitar a fadiga; possui anel em plástico com abertura, permitindo graduação.

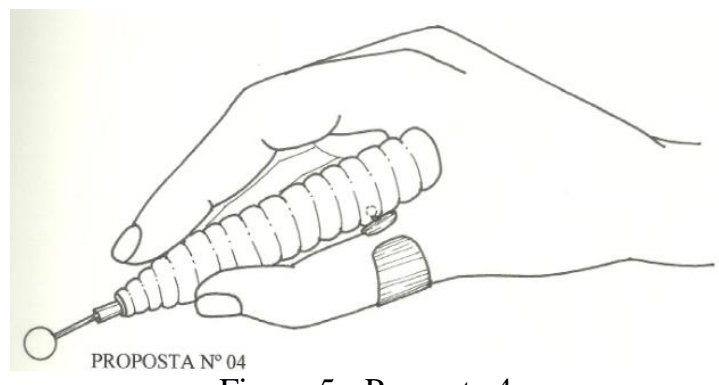

Figura 5 - Proposta 4.

Por fim, a proposta 5 (Figura 6) possui corpo em borracha e é abaulado no centro conformando-se à mão; liso a fim de evitar acúmulo de sujeiras no produto e com acomodação para o indicador e polegar. $6^{\circ}$ Ergodesign - Congresso Internacional de Ergonomia e Usabilidade e Interfaces Humano Tecnológica: Produto, Informações Ambientes onstruídos e Transporte

$6^{\circ}$ USIHC - Congresso Internacional de Ergonomia e Usabilidade de iterfaces Humano Computador

INAHPA | 2017 - Congresso Internacional de Ambientes Hipermídia ara Aprendizagem.

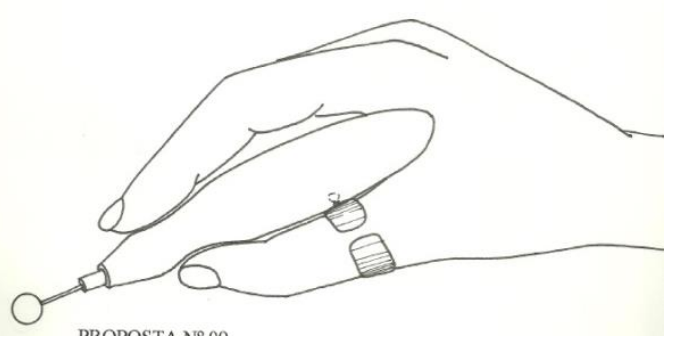

Figura 6 - Proposta 05.

\subsection{Proposta definida}

A proposta escolhida, considerando os requisitos já citados, apresenta corpo em borracha, abaulado no centro conformando-se à mão. Liso evitando sujeiras; ponteiras em borracha evitando o deslizamento entre as teclas; o anel plástico com abertura permite o descanso da mão, movimento de giro e consequentemente maior liberdade A forma é simples; funcional (o usuário não depende de outros para abrir; fechar ou manusear o produto); visa proporcionar segurança e conforto ao usuário.

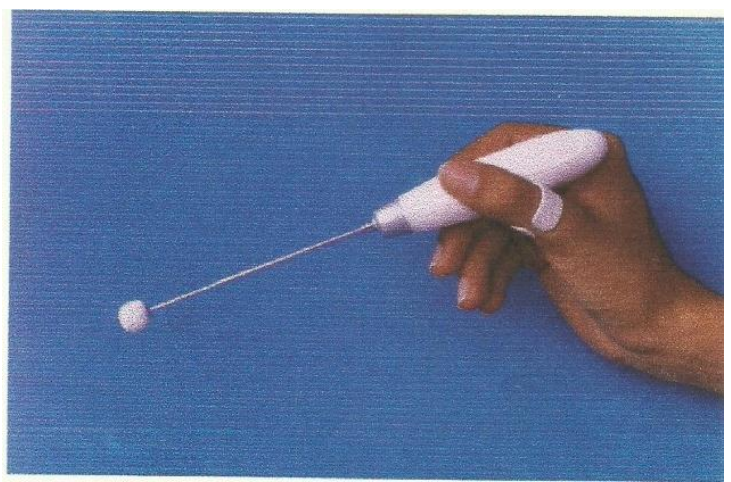

Figura 7: proposta definida.

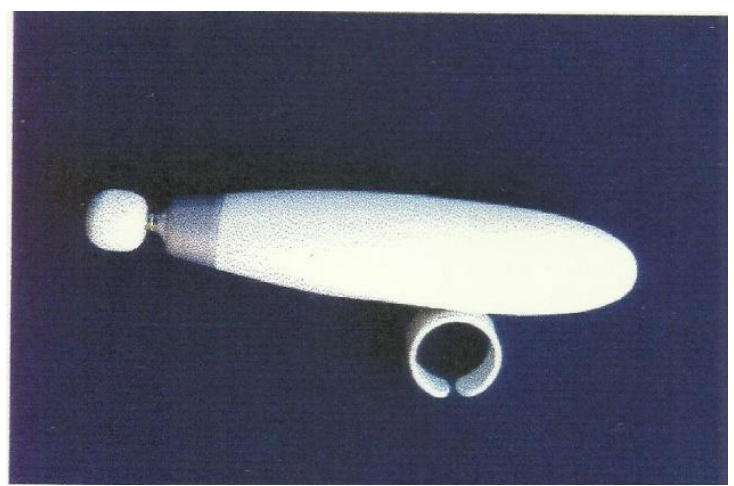

Figura 8: modelo final da proposta definitiva (fechado). 


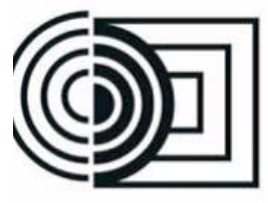

ERGODESIGN USIHC CINAHPA

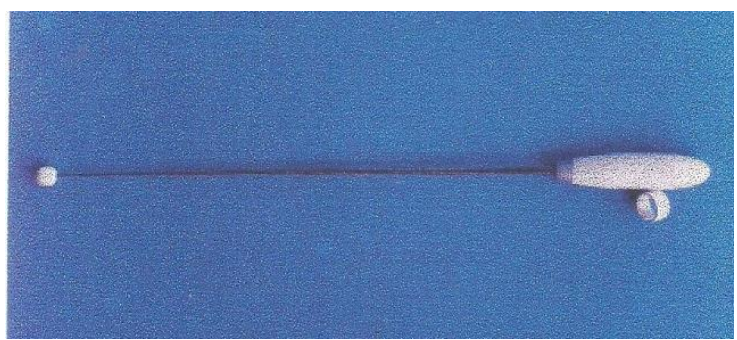

Figura 9: modelo final da proposta definitiva (aberto).

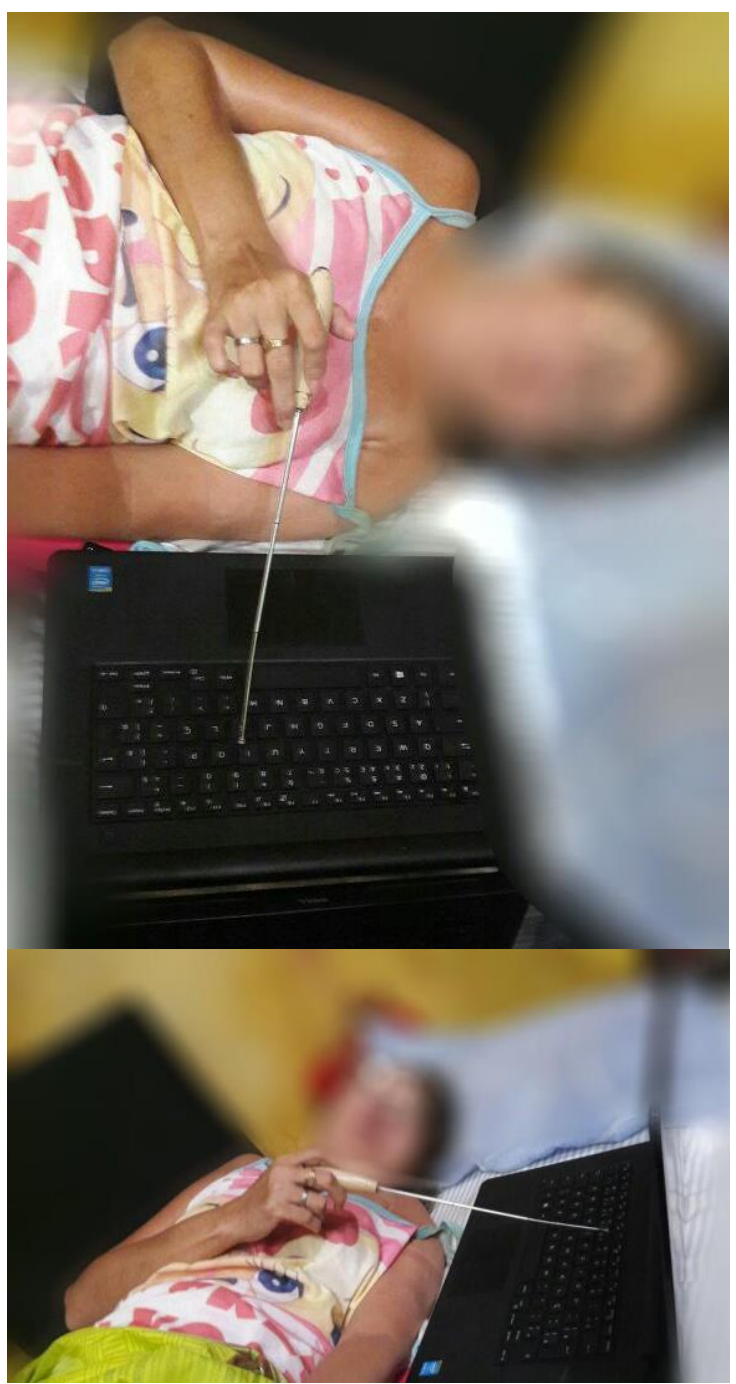

Figura 10: Usuária utilizando o produto para digitar em um teclado de notebook.

\section{Considerações Finais}

Assim, desenvolveu-se o projeto de um facilitador para digitação que possibilita ao $6^{\circ}$ Ergodesign - Congresso Internacional de Ergonomia e Usabilidade e Interfaces Humano Tecnológica: Produto, Informações Ambientes onstruídos e Transporte

$6^{\circ}$ USIHC - Congresso Internacional de Ergonomia e Usabilidade de iterfaces Humano Computador

INAHPA | 2017 - Congresso Internacional de Ambientes Hipermídia ara Aprendizagem.

usuário alcançar todo o teclado do computador, possui boa funcionalidade, pois é de fácil manuseio, a usuária leva-o consigo para qualquer lugar, consegue abrir e fechar sem auxílio de outros. O produto dá estabilidade proporcionando boa empunhadura; a ponteira em borracha evita o deslizamento entre as teclas e o anel plástico com abertura permite o descanso da mão sem deixar cair o facilitador, a esfera junto ao anel colocada na parte interna do corpo permite o giro da mesma e consequentemente um grande movimento e alcance.

O estudo de similares foi muito importante para o desenvolvimento do produto em questão que é especificamente para uma pessoa e uma deficiência específica, podendo ser adaptada para outras pessoas com diferentes síndromes. $\mathrm{O}$ acessório possui 6 (seis) peças, sendo parte delas em metal e a outra em elastômero (borracha e plástico).

O processo de fabricação das peças metálicas (aço, carbono ou inox) é usinagem, essas peças não serão fabricadas para este produto, pois já existem no mercado precisando apenas serem adaptadas para o mesmo. O processo de fabricação das partes em borracha e plástico (elastômero poliuretano: PU; densidade, 1,201,30; termoplástico) é a injeção.

Sugerimos ainda um material alternativo para as peças em elastômero a madeira podendo ela ser: marupá; mogno; cedro; louro-rosa; tauarí ou freijó, pois são macias e de baixa densidade: $50 \mathrm{~g} / \mathrm{m}^{3}$; podendo ser encontradas facilmente na região, neste caso o produto pode ser laqueado para um melhor acabamento ou apenas envernizado.

O acessório está em uso contínuo há 20 anos pela usuária que o utiliza diariamente como auxílio para alcance das teclas do computador. $\mathrm{O}$ acessório também já foi utilizado em urnas eletrônicas pela mesma.

Atualmente a usuária possui 45 anos, é pedagoga e especialista em educação inclusiva e especial e tem seu tempo bastante ocupado,
Realização:

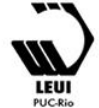




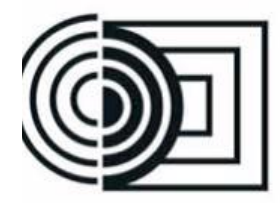

estuda para a seleção de mestrado, faz curso de espanhol, trabalha pelos direitos da pessoa com deficiência, é Coordenadora do Coletivo de Mulheres com Deficiência, do Fórum de Entidades de Pessoa com Deficiência e Patologia. Fez a faculdade se deslocando de ônibus e com a ajuda de uma amiga. Atualmente desloca-se principalmente de carro com a ajuda de uma amiga.

Em decorrência do avanço da FOP, atualmente a usuária está mais atrofiada e um novo acessório necessita ser desenvolvido considerando o estágio atual da doença. Entretanto ela relata que o acessório foi muito utilizado durante anos e que ultimamente continua usando, só que com menos frequência devido ao atual estágio da doença. Mas ainda utiliza para digitar em seu computador e para votar.

\section{Referências Bibliográficas}

ARAUJO JUNIOR, C. R. de, et al.

Fibrodisplasia ossificante progressiva: relato de caso e achados radiográficos. Radiol Bras, São Paulo, v. 38, n. 1, p. 69-73, Feb. 2005. Disponível em:

$<$ http://www.scielo.br/scielo.php?script=sci_ar ttext\&pid=S0100-

$39842005000100014 \& \operatorname{lng}=e n \& n r m=i s o>$.

Acesso em: 20 Mar. 2017.

BERSCH, R.; TONOLLI , J. C. Tecnologia

Assistiva. 2006. Disponível em: <http://www. assistiva. com.br/>. Acesso em: 03 mar. 2017.

\section{BERSCH, R. Introdução à Tecnologia}

Assistiva. 2013. Disponível em: <http://www.assistiva.com.br/Introducao_Tec nologia_Assistiva.pdf $>$ Acesso em: $20 \mathrm{mar}$ 2017.

BRASIL. DECRETO No 3.298, DE 20 DE DEZEMBRO DE 1999. Disponível em: <http://www.planalto.gov.br/ccivil_03/decreto /d3298.htm>. Acesso em: 20 mar 2017. $6^{\circ}$ Ergodesign - Congresso Internacional de Ergonomia e Usabilidade e Interfaces Humano Tecnológica: Produto, Informações Ambientes onstruídos e Transporte

$6^{\circ}$ USIHC - Congresso Internacional de Ergonomia e Usabilidade de terfaces Humano Computador

INAHPA | 2017 - Congresso Internacional de Ambientes Hipermídia ara Aprendizagem.

<http://www.planalto.gov.br/ccivil_03/_ato20 07-2010/2009/decreto/d6949.htm>. Acesso em: 20 mar. 2017.

CAVALCANTI, A. \& GALVÃO, C. Terapia ocupacional, fundamentação \& prática. Rio de Janeiro, Guanabara Koogan, 2007.

CIRÚRGICAEXPRESS. Belo Horizonte, 2015. Disponível em: <https://www.cirurgicaexpress.com.br>. Acesso em: 27 mar. 2017.

\section{COOK, A.M.; HUSSEY, S. M. Assistive}

Technologies: Principles and Practices. St. Louis: Mosby - Year Book Inc., 1995.

GARCIA-PINZAS, J.; WONG, J. E. B.; FERNÁNDEZ, M. A. P.; ROJAS-ESPINOZA, M. A. Fibrodysplasia ossificans progressiva: diagnosis in primary care. Rev. paul. pediatr., São Paulo, v. 31, n. 1, p. 124-128, Mar. 2013. Disponível em:

$<$ http://www.scielo.br/scielo.php?script=sci_ar ttext\&pid=S0103-

$05822013000100020 \& \operatorname{lng}=\mathrm{en} \& \mathrm{nrm}=\mathrm{iso}>$.

Acesso em: 20 Mar. 2017.

INTERNATIONAL ORGANIZATION FOR STANDARDIZATION: ISO 9999:2011 Produtos de apoio. Disponível em: $<$ http://www.eastin.eu/ptpt/searches/products/iso/0612>. Acesso em: 25 de mar. 2017.

LÖBACH, B. Design Industrial: bases para a configuração de produtos industriais. 1a ed., São Paulo: Editora Edgard Blücher Ltda., 2001. 